\title{
The Teaching of Cognitive Therapy in Newcastle
}

Jan Scott, Registrar in Psychiatry; W. A. BARKer, Lecturer in Psychiatry, Department of Psychological Medicine, Newcastle-upon-Tyne; and J. MARK G. Williams, Scientific Officer, MRC Applied Psychology Unit, Cambridge

Cognitive therapy (CT) is now widely recommended as an effective form of psychological treatment for a variety of psychiatric disorders, particularly depressive and anxiety states.' The therapy itself consists of a specific treatment 'package' derived from the cognitive theory of psychopathology and seems to have developed because of a growing dissatisfaction with dynamic psychotherapy on the one hand, and a strictly behavioural approach to the patient's difficulties on the other. ${ }^{2}$ A further factor has been the unwillingness of some patients to continue for long periods on psychotropic medication and the unwillingness of medical practitioners to prescribe it in patients who have expressed suicidal ideas, or have not previously responded well to medication. The main thrust of the CT is problem orientated, and treatment itself is an active, moderately directive, time-limited, structured approach set in the present in which the patient and therapist work in collaboration to relieve the patient's symptoms. ${ }^{3,4}$

The demand for knowledge and training in the country is now quite overwhelming. In Newcastle upon Tyne the local interest shown has led to the organization of regular one-day workshops on the subject. The workshops are run twice yearly and those attending have been drawn from many of the disciplines involved in the care of psychiatric patients, including psychiatry, clinical psychology and social work. Over the course of the day the theoretical rationale, the techniques used in therapy and the appropriate uses, and limitations, of this type of approach are discussed. These workshops have been well received, with many of those attending going on to use CT in their own clinical practice. A system of 'intermediate workshops' has also recently been introduced in which experienced therapists from the region can discuss areas of difficulty they have encountered, or new areas they wish to explore.

\section{The CT workshop}

Prior to the workshop, participants are sent a selection of the literature on cognitive theory and therapy as an introduction to the concepts used. The workshop is designed around teaching sessions for the whole group, supplemented by small group work, open discussion and feedback.

The introductory session is a review of the development of cognitive theory, and the practice of the therapy is outlined. Although some of the core cognitive and behavioural techniques are described in some detail, emphasis is placed on the psychotherapeutic nature of the therapy and the consequent importance of therapist attributes. The presentation is illustrated by transcripts and audiotapes of actual CT sessions, in order to demonstrate the technique more fully. The main group then splits into subgroups of four or five, each of which is led by a psychologist or psychiatrist experienced in the application of CT. The small group allows each individual the opportunity to try out the techniques through selected training exercises which consist of specific examples of the problems encountered in therapy. Each member in turn takes on the role of therapist, with the patient role-played by another member of the group. The techniques involved in CT can thus be practised in the presence of the experienced therapist who acts as observer and adviser. The small group work is then discussed in the large group setting. The rest of the workshop follows a similar pattern. Selected areas of therapy, such as the depressed suicidal patients, are presented in an introductory talk, and appropriate treatment strategies are described. These are examined in detail in the sub-groups, through role-play and discussion. Time is also allocated throughout the day to 'feedback' in the large group and to allow general discussion of the theory. Inevitably, informal discussion also continues through the breaks for refreshments and lunch.

\section{Which techniques to select}

There are many techniques at the disposal of the cognitive therapist-Williams $s^{4}$ lists nineteen that have been used in outcome studies of CT. Clearly it is impossible to give even the briefest introduction to such a large range. We have found by trial and error that concentrating on the four core techniques of 'task assignment', 'thought catching', 'cognitive rehearsal' and 'alternative therapy' offers the best introduction. In addition, role playing that part of the initial interview in which the therapist is explaining what CT is about has proved a sensitive measure of how comfortable both role-players feel with the concepts and techniques of the therapy.

\section{The CT group}

The workshop can only act as an introduction to CT, it is not expected to produce expert therapists, but rather it is a way of raising general awareness of the issues and techniques, so that participants who are particularly interested in developing their skills may seek further training. For example, out of the workshops have grown a multidisciplinary group which meets fortnightly. It acts as a central forum for discussion, particularly for problems, and as such serves as a valuable support. The more experienced members supervise new members, as well as one another, and each discipline has a significant and useful role to play, adding to the overall skills and knowledge of group members. New patients referred for CT can be allocated to an appropriate therapist, and group leaders for future CT workshops can be drawn from the ranks of the group.

\section{CT for psychiatrists in training}

As CT is fast becoming an important addition to established psychological treatments for many psychiatric 
problems, ${ }^{3}$ trainees in psychiatry should have some awareness of this type of approach and a knowledge of the strategies used. In this way, even those who do not wish to apply the techniques themselves will at least be able to select and refer patients appropriately.

Many psychiatrists not using CT harbour misconceptions about what is involved: that $\mathrm{CT}$ is only what clinicians do already; that it is unsuitable for endogenoustype depressives; that CT involves 'talking the patient out of their worries". These and other perceived problems with CT are discussed by Williams. ${ }^{6}$ Finally, some clinicians hold that CT merely systematizes good clinical practice. In fact, this type of treatment involves a particular therapeutic style as well as the application of a set of techniques and requires a significant conceptual shift for many psychiatrists. The patient and therapist must collaborate to carry out an empirical investigation of the patient's thoughts and assumptions about themselves, their world and their future. The aspiring cognitive therapist also needs to be able to conduct the sessions in a warm, empathic and accepting manner, gently challenging the patient to think of ways in which they can test out their maladaptive thoughts without making them feel they are being confronted. It therefore gives the trainee the opportunity to develop good psychotherapeutic skills in a more structured and directive setting than that usually afforded by dynamically orientated psychotherapy, although it by no means replaces teaching and experience in these other schools.

$$
\text { REFERENCES }
$$

'Gelder. M. G. (1983) Is cognitive therapy effective?: Dis cussion paper. Journal of the Royal Society of Medicine. 76, 938-42.

'Rush, A. J. (1982) Short-Term Psychotherapies for Depression. New York: John Wiley and Sons.

'Beck, A. T., Rush, A. J., Shaw, B. F., Emery, G. (1979) Cognitive Therapy of Depression. New York: John Wiley and Sons.

'Williams. J. M. G. (1984) The Psychological Treatment of Depression. London: Croom Helm.

'Goldberg, D. (1982) Cognitive therapy for depression. British Medical Journal, 284, 143-44.

'WILliams, J. M. G. (1984) Cognitive-behaviour therapy in depression: problems and perspectives. British Journal of Psychiatry, 145, 254-62.

\section{An Open Letter to the President from the Collegiate Trainees' Committee}

\section{DEAR DR BEWLEY}

At the present time there are 1,066 whole-time equivalent (wte) consultant psychiatrists practising in the field of adult mental illness in England and Wales. These consultants are training 248 wte senior registrars and 762 wte registrars. If the Short Report recommendations (of doubling the number of consultants and reversing the ratio of consultants to trainees) are implemented then 2,132 wte consultants will need to train approximately 426 wte senior registrars and no more, possibly fewer, wte registrars. (The ratio of five consultants to one senior registrar has been used which assumes an average working life of 20 years for a consultant and 4 years' training for a senior registrar. This ratio is currently used in Scotland, in all specialties, to calculate the senior registrar establishment, yearly, on the basis of projected consultant vacancies.)

The CTC is alarmed that despite the fact that the Government has accepted the bulk of Short's recommendations there is no striking evidence as yet of its implementation, with the lamentable exception of efforts to reduce junior posts without consultant expansion. As the College has also endorsed the bulk of the Short Report one might have expected more protest than has yet been seen.

However, even if the Short proposals are never implemented, the College's own long-term goal of one consultant to 25,000 population would also lead roughly to a doubling of the number of consultant psychiatrists and the institution of a realistic career structure in psychiatry would demand the same numbers of juniors as are derived above for implementation of the Short proposals.

Coupled with recent complaints that by setting more stringent requirements the Approval Exercise is affecting service provision (Bulletin, April 1984, 8, 74-75; Hospital Doctor, 9 November 1984, p. 4), it would seem inevitable that in future a proportion of consultant psychiatrists will have to work without the support of trainees. There is therefore a need to face up to this unpalatable reality.

It has been suggested that the College should study those units already providing a consultant only service and also look more to the approval of posts rather than hospitals in order that more hospitals will maintain a trainee presence (Bulletin, July 1984, 8, 122-23). Whilst the CTC would support these two suggestions and believes that all training schemes should incorporate posts outside teaching centres, to prevent trainees being concentrated in the latter, there is also a need for wider action. Much of the reluctance to think in terms of a consultant provided service, both from seniors and juniors, must be attributable to the effects of training and working in one model of service.

In order that the prospect of working in this way is seen as a challenge by some, rather than a booby prize by all, it would seem logical to introduce this model of service during training - at a time when young psychiatrists are at their most creative-rather than attempt to impose it on mature clinicians out of necessity.

The CTC wishes to know when the College will grasp this nettle.

Yours sincerely,
J. A. Hollyman

Chairman
Collegiate Trainees' Committee,

Roval College of Psychiatrists 